\title{
THE ART OF APPLICATION OF HIGH-STRENGTH STEEL STRUCTURES FOR BUILDINGS IN SEISMIC ZONES
}

\author{
Guo-Qiang $\mathrm{Li}^{1}$, Yan-Bo Wang ${ }^{2,}$ and Su-Wen Chen ${ }^{1}$ \\ I. State Key Laboratory for Disaster Reduction in Civil Engineering, Tongji University, China \\ 2. College of Civil Engineering, Tongji University, Shanghai, China \\ *(Corresponding Author: E-mail: ybwang@tongji.edu.cn)
}

\begin{abstract}
Since recent advances of technology in material science and increasing demand for high strength materials, high-strength steel (HSS) has been applied to several landmark buildings and major projects. However, the application of high-strength steel in seismic structures is limited by the relative worse ductility, which usually decreases with the increase in yield strength. In this paper, key issues associated with the application of HSS in seismic structures are pointed out and discussed. The current state of the art of behavior of HSS and recent research on the seismic behavior of HSS carried out at Tongji University are presented. The effect of reheating and cooling during fabrication process on the mechanical properties of HSS is evaluated. Through the revisit and reconsideration on the basic level of seismic design philosophy, two new design methodologies for application of HSS structures for buildings in seismic zones are proposed. Finally, future works related to the application of high strength steels are recommended.
\end{abstract}

Keywords: High-strength steel, Seismic design, Application, Recent research

\section{INTRODUCTION}

Due to the architectural and structural advantages, high-strength steel (HSS, yield stress $\geq 460 \mathrm{MPa}$ ) has been increasingly used in high-rise buildings, large span buildings and bridges in the past two decades $[1,2]$. Compared with regular mild carbon steel members, the application of HSS members shows the following advantages:

- In lieu of conventional mild carbon steels, adoption of high-strength steels can reduce plate thickness and member size because of the increased allowable design stress.

- Consequently, the usable floor area of the structures could be increased and the self-weight of the structures could be reduced. Moreover, special architectural form leads to many difficulties in structural design. Thus, light weight and slim members are usually desirable.

- As a result of the reduction in plate thickness and member size, difficulties in welding thick plates and the amount of welding can be reduced.

- Owing to the lighter self-weight of structures, savings may be made in transportation and erection, and smaller foundations could be constructed.

- Mass-dependent dynamic forces, such as earthquake actions, can be reduced.

The price of high-strength steel is usually higher than the price of normal-strength steel. However, the increase in steel price is lower than the increase in steel strength. Thus, when providing with the same strength, the cost of high-strength steel is actually lower than the cost of normal-strength steel. The normalized prices of different steel grades of ref. [3] are reproduced here, as shown in Figure 1. If the strength can be fully utilized, it is economical to use high-strength steel in structures. With the recent development of steelmaking techniques and advances in welding techniques, HSS members can be produced at a reasonable cost with good quality in China. According to World Steel Association [4], there was an increase of $68 \%$ in steel production worldwide between 2000 
and 2010, with China experiencing an increase of 396\% for the same period, as shown in Figure 2. Similarly, global use of steel had increased $69 \%$ from 2000 to 2010 , while the use of steel in China had increased over $400 \%$ for the same period. Because of the rapid industrialization and urbanization, China accounted for approximately $45 \%$ of the global steel production in 2010 [5], as shown in Figure 3. More than half of steel consumption was devoted to construction, which was the greatest steel market share in 2010.

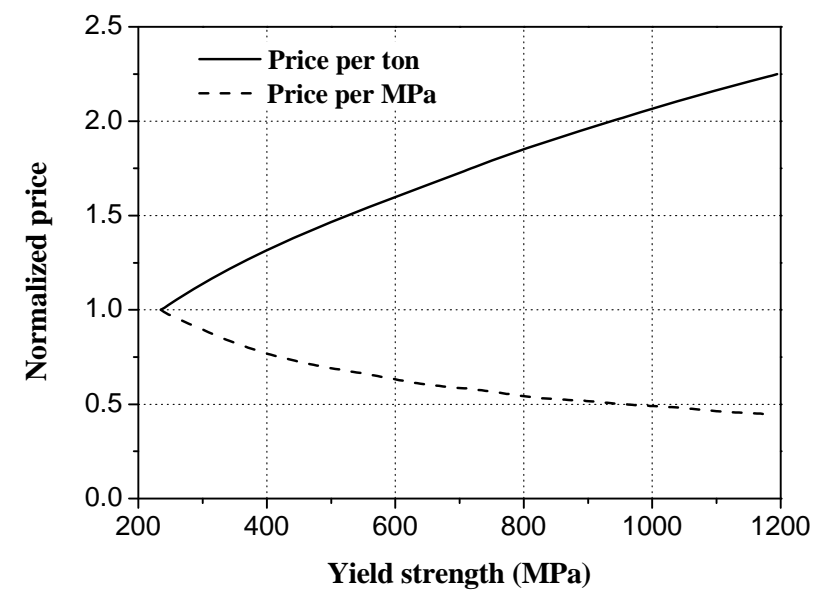

Figure 1. Comparison of Normalized Price among Different Steel Grades

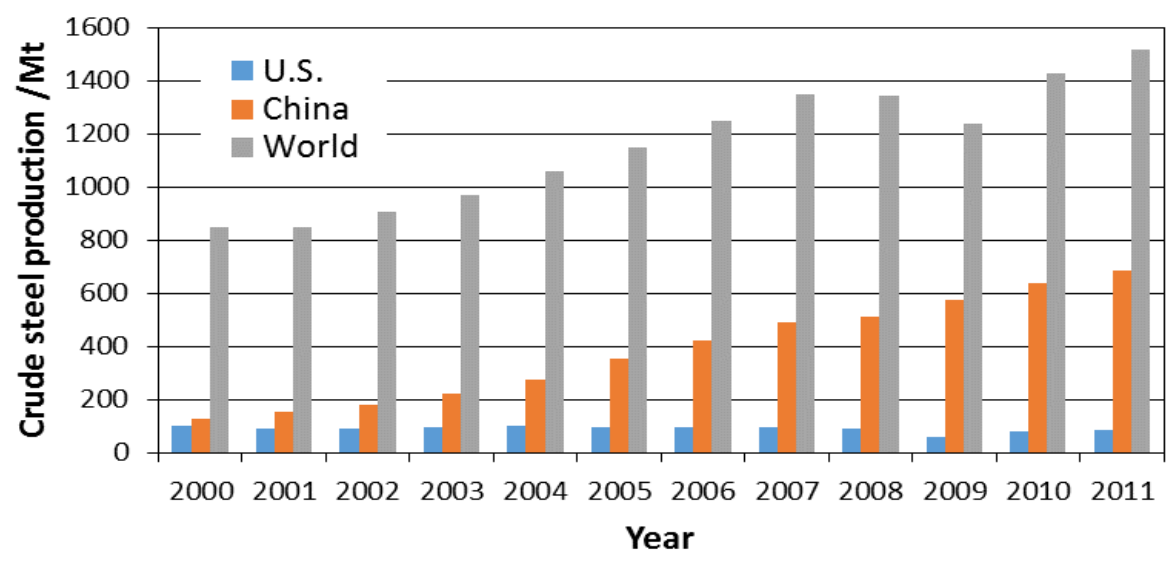

Figure 2. Annual Crude Steel Production

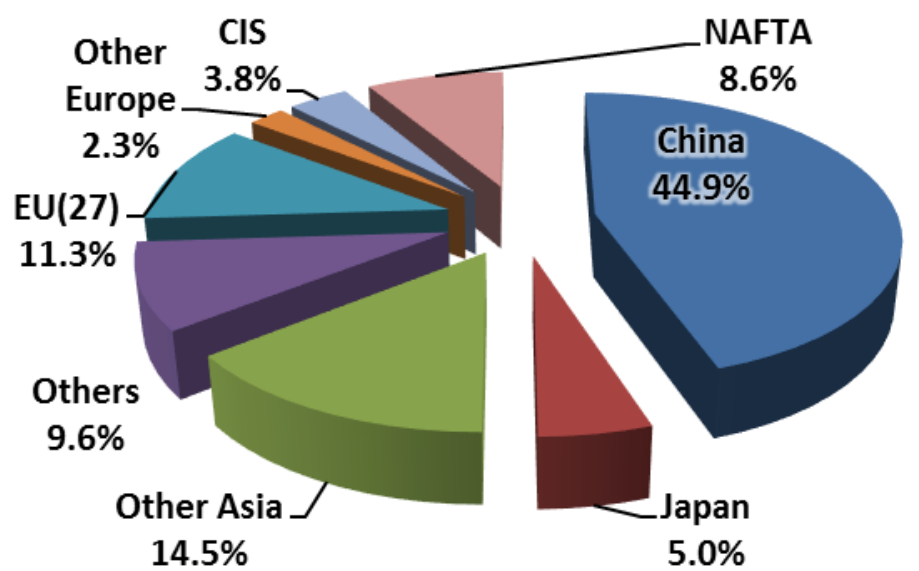

Figure 3. Global use of Steel in 2010 
However, the use of HSS is limited by current Chinese Code for Design of Steel Structures GB 50017-2003 [6] and Code for Seismic Design of Buildings GB 50011-2010 [7]. The former limits structural steel grade up to Q420 (with nominal yield strength of $420 \mathrm{MPa}$ ). The later requires a higher ductility of steels due to the expectation of inelastic behavior of structural elements and connections under rare earthquakes. With the increase in material strength, the yield to tensile strength ratio (Y/T ratio) and elongation ratio of HSS could hardly meet the requirements of GB 50011-2010 [7]. According to the annual report of China Steel Construction Society in 2010, the most used steel is Q345, which takes $62 \%$ of the total steel consumption, while Q460 HSS only takes $1 \%$ of the total consumption, as shown in Figure 4. Consequently, the necessity of requirements to investigate whether the members fabricated from HSS can be designed according to the existing codes or whether the codes need to be modified to include HSS is highlighted. Moreover, it is important to determine whether HSS could be used in seismic structures and how to use HSS in seismic structures.

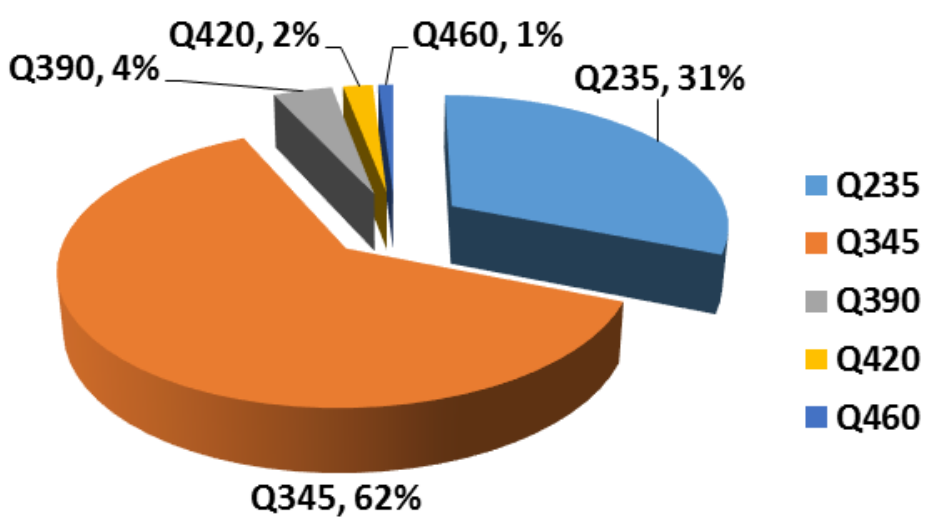

Figure 4. The Percentage of each Steel Grade Consumed in 2010 of Mainland China

In this paper, the key issues associated with the application of HSS in seismic structures are pointed out and discussed. The current state of the art of behavior of HSS and recent research on the seismic behavior of HSS carried out at Tongji University are presented. The effect of reheating and cooling during fabrication process on the mechanical properties of HSS is evaluated. Through the revisit and reconsideration on the basic level of seismic design philosophy, the design methodologies for application of HSS structures for buildings in seismic zones are proposed.

\section{LIMITS RELATED TO THE APPLICATION OF HSS IN SEISMIC RESISTANT STRUCTURES}

\subsection{Effect of Mechanical Properties on the Ductility of Structural Members}

It is expected that structures will undergo a certain degree of inelastic deformation under earthquake actions. Thus, structural members must process adequate ductility to dissipate earthquake energy. Previous researches [8-10] indicate $\mathrm{Y} / \mathrm{T}$ ratio and elongation ratio play fundamental rules in the influence on the ductility of structural members. It is obvious the elongation ratio of material has a direct influence on the deformation capacity of structural members. Meanwhile, Y/T ratio has an indirect influence on the ductility of structural members, as shown in Figure 5. Figure 5(a) shows a perforated or reduced tensile member, where $f_{y}$ is the yield strength, $f_{y}<f_{p} \leq f_{u}, f_{u}$ is the tensile strength, $N_{y}=A f_{y}, N_{p}=A_{n} f_{p}, A$ is the area of cross section, $A_{n}$ is the net area of reduced cross section. If the $\mathrm{Y} / \mathrm{T}$ ratio is high enough to result in 
$N_{y}>N_{P}$, the inelastic deformation will be localized in the reduced zone. Although the material itself has a good deformability, the ductility of the member will be significantly impaired by the localized deformation. Figure 5(b) shows a flexural member, where $M_{y}$ is the yield bending moment, $M_{p i}$ is the plastic bending moment. If the $\mathrm{Y} / \mathrm{T}$ ratio is close to 1 , the development of plastic zone in beam ends will be limited within a very short segment because the values of $M_{p 1}$ and $M_{p 2}$ are close. Consequently, the rotation capacity of the beam, which represents the ductility of flexural members, will be jeopardized.

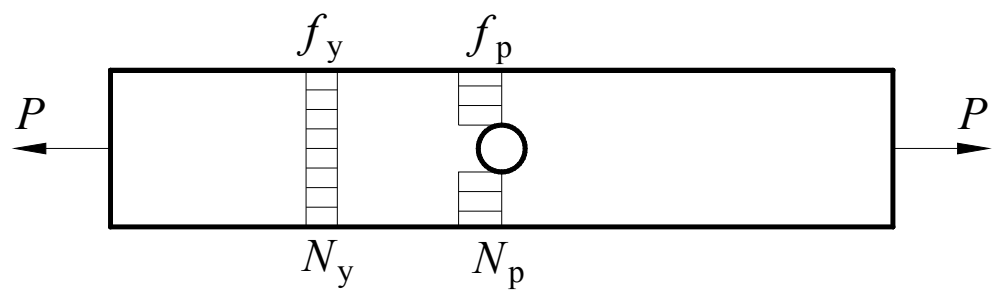

(a) Reduced members

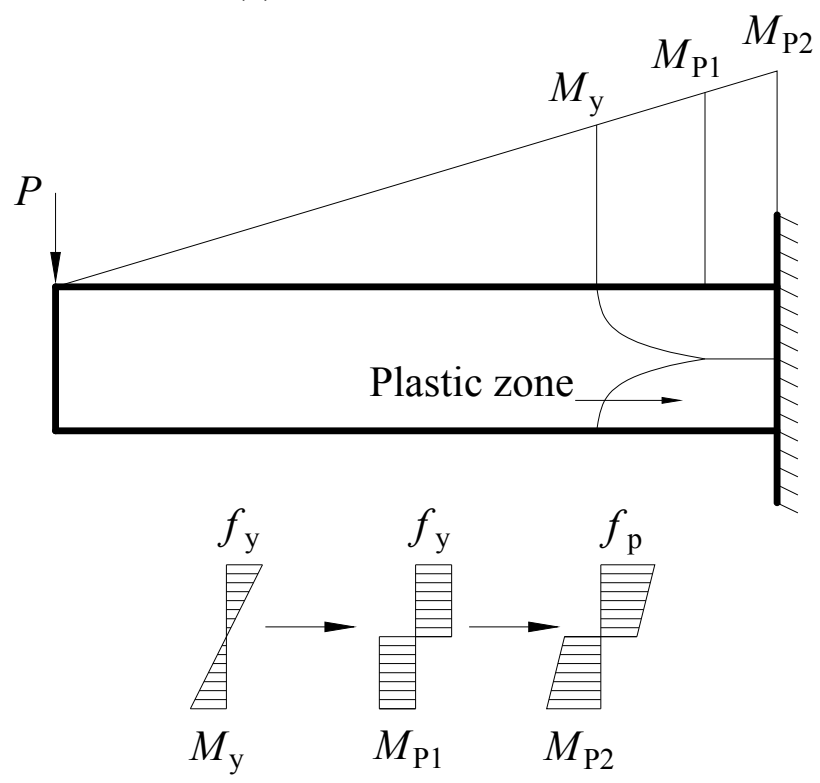

(b) Flexural members

Figure 5. The Effect of Yield Ratio on the Ductility of Members

\subsection{Limits of Current Design Codes}

The limits on Y/T ratio and elongation ratio have been specified in GB 50017-2003 [6] and GB 50011-2010 [7] to ensure the ductility and deformability of structural members, as summarized in Table 1. Compared to GB 50017-2003, seismic design code GB 50011-2010 has more strict limits on Y/T ratio and elongation ratio. Requirements of material ductility specified in Eurocode3 [11] and Eurocode8 [12] utilize the parameters of tensile to yield strength ratio $\left(f_{\mathrm{u}} / f_{\mathrm{y}} \geq 1.10\right)$, elongation ratio (no less than 15\%) and ultimate strain (not less than 15 times of the yield strain). According to Chinese Code for Seismic Design of Buildings GB 50011-2010 [7], the ductility requirement of steel is higher than Eurocode3 due to the consideration of inelastic behavior of structural members and connections under rare earthquakes. Based on the tensile coupon tests of various steel grade, Fukumoto [13] pointed out that the increase in strength will result in the increase in Y/T ratio and the decrease in elongation ratio, which indicates the HSS could hardly meet the ductility requirements for seismic design. For comparison with Table 1, the limits of material requirements 
specified in Steel Plates for Building Structure GB/T 19879-2005 [14] and High Strength Low Alloy Structural Steels GB/T 1591-2008 [15] are shown in Table 2 and Table 3, respectively. It can be seen that steel plates with nominal yield strength no less than $420 \mathrm{MPa}$ could not meet the ductility requirements of GB 50011-2010.

Table 1. Comparison of Requirements of Mechanical Properties GB 50011-2010 GB 50017-2003

1. Yield to tensile strength ratio $\leq$ 0.85

1. Yield to tensile strength ratio $\leq 0.83$

2. Ratio of elongation after failure $\geq 20 \%$

2. Ratio of elongation after failure $\geq 15 \%$

3. $\varepsilon_{u} \geq 20 \varepsilon_{y}$

3. Well defined yielding plateau

Table 2. Requirements of Mechanical Properties in GB/T 19879-2005

\begin{tabular}{ccccc} 
Steel grade $\begin{array}{c}\text { Yield strength Tensile strength } \\
(\mathrm{MPa})\end{array}$ & $\begin{array}{l}\text { EPa }) \\
\text { Elongation Y/T ratio }\end{array}$ & & \\
\hline Q235GJ & $\geq 235$ & $400 \sim 510$ & $\geq 23 \%$ & $\leq 0.80$ \\
Q345GJ & $\geq 345$ & $490 \sim 610$ & $\geq 22 \%$ & $\leq 0.83$ \\
Q390GJ & $\geq 390$ & $490 \sim 650$ & $\geq 20 \%$ & $\leq 0.85$ \\
Q420GJ & $\geq 420$ & $520 \sim 680$ & $\geq 19 \%$ & $\leq 0.85$ \\
Q460GJ & $\geq 460$ & $550 \sim 720$ & $\geq 17 \%$ & $\leq 0.85$ \\
\hline
\end{tabular}

Table 3. Requirements of Mechanical Properties in GB/T 1591-2008

\begin{tabular}{ccccc}
\hline Steel grade $\begin{array}{c}\text { Yield strength Tensile strength } \\
(\mathrm{MPa})\end{array}$ & $\begin{array}{l}\text { Elongation } \mathrm{Y} / \mathrm{T} \text { ratio } \\
(\mathrm{MPa})\end{array}$ & \multicolumn{2}{c}{ El } & \\
\hline Q345 & $\geq 345$ & $470 \sim 630$ & $\geq 20 \%$ & $\leq 0.73$ \\
Q390 & $\geq 390$ & $490 \sim 650$ & $\geq 20 \%$ & $\leq 0.80$ \\
Q420 & $\geq 420$ & $520 \sim 680$ & $\geq 19 \%$ & $\leq 0.81$ \\
Q460 & $\geq 460$ & $550 \sim 720$ & $\geq 17 \%$ & $\leq 0.84$ \\
Q500 & $\geq 500$ & $610 \sim 770$ & $\geq 17 \%$ & $\leq 0.82$ \\
Q550 & $\geq 550$ & $670 \sim 830$ & $\geq 16 \%$ & $\leq 0.82$ \\
Q620 & $\geq 620$ & $710 \sim 880$ & $\geq 15 \%$ & $\leq 0.87$ \\
Q690 & $\geq 690$ & $770 \sim 940$ & $\geq 14 \%$ & $\leq 0.90$ \\
\hline
\end{tabular}

\subsection{Limits of Current Researches on HSS}

In aiming to extend current steel structure design codes to include HSS, recent researches have been performed on the behavior of HSS structural members under monotonic loading. The experimental and numerical investigations on HSS beams [16-19] have shown that yield strength and yield to ultimate strength ratio has significant influence on the rotation capacity of beam members. Compared with conventional steel, the rotation capacity of HSS beam with identical cross-sectional geometry was reduced by over $70 \%$. Although the current specifications are able to predict the flexural strength of HSS beams, the existing compactness criteria cannot guarantee the required rotation capacity for HSS members. Previous researches on ultimate bearing capacity, local and overall buckling behavior of HSS columns [20-24] have shown that the effects of initial geometric imperfection and residual stress on the buckling behavior of HSS columns are less detrimental than those on normal strength steel columns. The current steel structure design standards are slightly conservative for HSS. Minor modifications of existing design codes might be necessary to include the design of HSS structures in non-seismic regions. 
However, it is not economical to design structures as assuming them in elastic range under severe earthquake. Thus, it is recommended that structures shall be able to endure certain inelastic deformation to dissipate earthquake energy. The energy dissipation capacity of structure depends mainly on the energy dissipation capacity of structural members, which is not only a function of mechanical properties, but also affected by cross-sectional geometry and loading conditions. Currently, the application of HSS in seismic design is restricted by existing seismic design codes and constructional practice, which are established based on the study of conventional steel. Therefore, the seismic performance of HSS should be examined when it was related to the application of HSS in structural design for earthquake-resistance. Therefore, better understanding of inelastic cyclic behavior of HSS, as well as the seismic performance of HSS structural members, is important for determining the suitability of application of HSS for seismic resistant structure.

Currently, only limited investigations on the cyclic behavior and hysteretic model of HSS have been reported on the literatures. Dusicka et al. [25] investigated the inelastic cyclic behavior and low-cycle fatigue life of plate steels with the nominal yield strength up to $485 \mathrm{MPa}$. Ramberg-Osgood model was used to fit the experimental skeleton curves and the associated coefficients were obtained from data regression of the test result. Although the power function based on the Ramberg-Osgood model seems efficient to describe the nonlinear part of the cyclic skeleton curve, it is inconvenient to be implemented in numerical analysis in structural level due to the implicit expression of stress in the power function. To this end, an explicit expression of stress in terms of rational function with four fitting parameters was proposed by Shi et al. [26]. The model parameters were calibrated by Q460D steel (nominal yield strength of $460 \mathrm{MPa}$ ) based on the test results of 17 coupon specimens. However, in the previous researches, the verification of hysteretic model for HSS was limited to the material level. This is mainly attributed to the scarcity of test data of seismic behavior of HSS members, which highlights the necessary for an extensive study on cyclic response of HSS members. Moreover, further evaluation on the effect of mechanical properties on the cyclic behavior and energy dissipation capacity of HSS structural members is required.

\section{MECHANICAL PROPERTIES AFTER REHEATING AND COOLING DURING FABRICATION PROCESS}

According to Chinese code GB/T 1591-2008 [15] and European code EN 10025-6 [27], HSSs are currently delivered in the quenched and tempered condition and thermo-mechanically controlled processed (TMCP) condition. Both quenching and TMCP have a controlled-cooling process, which is usually an accelerated cooling process by water, oil, or forced-air, to get the preferred crystalline phases of the alloy and the finer grain size. The cooling speed is an important factor for the ductility and strength of steels. However, fabrication process such as flame cutting, welding, and flame straightening will introduce a reheating and cooling process on the local area of steel members. The maximum temperature of flame cutting and welding is over $1200^{\circ} \mathrm{C}$. The maximum temperature of flame straightening is about $650^{\circ} \mathrm{C}-900^{\circ} \mathrm{C}$ depending on heating time. Similar as tempering, the experience of such high temperatures may produce a serious reduction in the strength and hardness of the heat-affected zones.

In order to evaluate the effect of reheating and cooling on the mechanical properties of HSS, tensile tests of 8 coupons were carried out from a flame straightened Q690D box column, as shown in Figure 6. The box column specimen was fabricated from $16 \mathrm{~mm}$ Q690D steel plate with the cross-sectional width and height of $250 \mathrm{~mm}$. Full-thickness heating and air cooling was applied on the triangular areas of webs and rectangular area of top flange. Tensile coupons are machined from the bottom flange and the heating areas of top flange and webs. Eight tensile coupons were tested in 
accordance with the specifications of GB/T 228-2002 [28], and the values of the tests are summarized in Table 4 . In the Table $4, E$ is the Young's modulus, $f_{y}$ is the $0.2 \%$ proof stress, which is adopted as the yield strength of steel, $f_{u}$ is the ultimate tensile stress, and $\delta$ is the percentage of elongation after fracture. It can be seen from Table 4, the effect of reheating and cooling on the elongation ratio should not be ignored. Compared with the bottom flange, the elongation ratio of heat-affected zone in top flange is reduced by up to $12 \%$. Moreover, the yield strength and tensile strength of top flange are reduced by $21 \%$ and $11 \%$, respectively. The reduction of yield strength is about twice of the reduction of tensile strength. The reductions of the yield and tensile strengths of webs are $18 \%$ and $9 \%$. Therefore, this influence of reheating during fabrication process should be considered in the design of HSS structures. Otherwise, the "premature" local and overall buckling and unexpected location of plastic hinge might appear in HSS structure to impair its seismic performance.

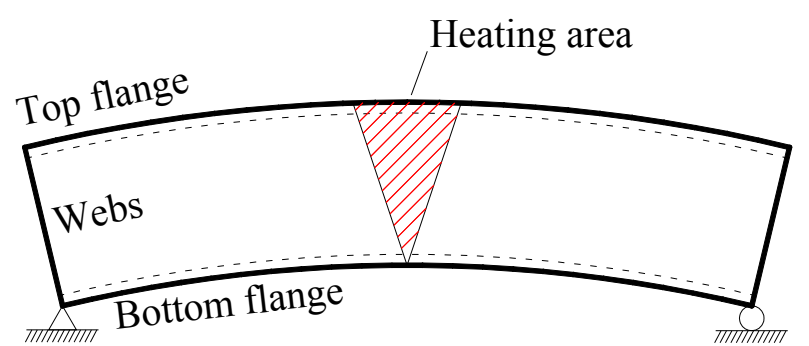

(a) Elevation view

Back web

Heating area

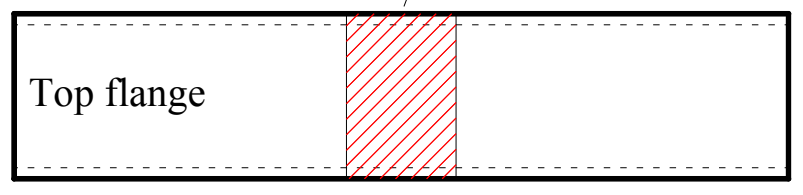

Front web

(b) Plane view

Figure 6. Flame Straightening of Box Column

Table 4. Mechanical Properties of Flame Straightened Q690D Steel

\begin{tabular}{ccccc}
\hline Specimens & $f_{y}(\mathrm{MPa})$ & $f_{w}(\mathrm{MPa})$ & $\tilde{f}_{y} / \tilde{f}_{\mathrm{w}}$ & $\delta(\%)$ \\
\hline \multirow{2}{*}{ Top flange } & 593.8 & 696.3 & 0.85 & 18.0 \\
Mean value & 600.4 & 728.3 & 0.82 & 18.6 \\
\hline \multirow{2}{*}{ Front web } & 597.1 & 712.3 & 0.84 & 18.3 \\
& 601.7 & 706.7 & 0.85 & 19.4 \\
Back web & 587.5 & 748.3 & 0.84 & 18.9 \\
Mean value & 653.1 & 712.8 & 0.82 & 19.6 \\
\hline \multirow{2}{*}{ Bottom flange } & 760.2 & 762.1 & 0.93 & 19.5 \\
Mean value & 746.9 & 732.5 & 0.9 & 19.3 \\
\hline
\end{tabular}

\section{RECONSIDERATIONS ON THE BASIC LEVEL OF SEISMIC DESIGN PHILOSOPHY}

The current seismic design philosophy is based on the assumption that structural members and connections can undergo a certain plastic deformation without a loss in structural bearing capacity under expected rare earthquake actions. The correctness of this assumption is ensured by the 
specified material requirements in current seismic design code. Accordingly, as HSS could not meet the material requirements, HSS members are not permitted to use in seismic structures. However, the application of HSS in seismic structures could be reconsidered in the level of seismic resistant design philosophy when we give up this assumption. Consequently, two design methodologies for HSS seismic resistant structures are proposed herein.

\subsection{Determination of Design Earthquake Action}

In view of structural performance under earthquake, design earthquake action could be reduced in accordance with the ductility of structures, as shown in Figure7. Structures with good ductility could be designed under a reduced earthquake loading, so the inelastic behavior of structures is expected under actual earthquake action and the earthquake energy could be dissipated by plastic deformation of members and connections. Instead, brittle structures should be designed under more serious earthquake actions than ductile structures to reduce the requirement of structural ductility.

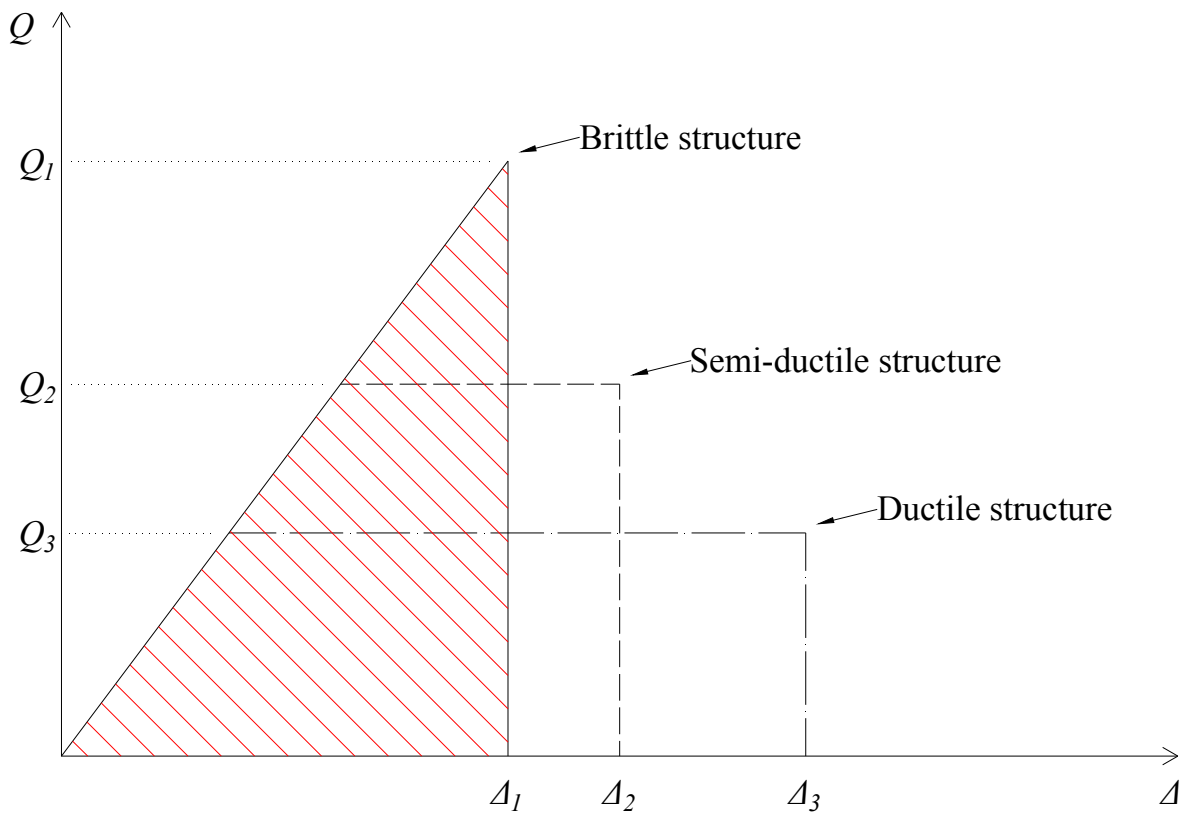

Figure7. The Effect of Ductility on the Requirement of Design Seismic Actions

\subsection{Selection of Structural Systems}

The design based on the assumption of preventing steel structures from inelastic status under expected rare earthquakes is usually uneconomical and unreasonable. Thus, seismic resistant buildings are mostly designed as dissipative structures which allow for the formation of plastic hinges in the expected locations, such as "strong column, weak beam" philosophy. However, the ductility of HSS members is not guaranteed to satisfy the demands of structural plastic behavior during earthquake actions. It is important to note that the ductility of structures, in addition to the ductility of materials and members, also depends on the selection of structural systems. If an appropriate structural system is selected for HSS structures, the plastic deformations can be isolated in the specified dissipative members to prevent the yield of HSS members.

One of such suggested structural systems is consisted of semi-rigid frames and special energy dissipation members, as shown in Figure 8. Semi-rigid frames can provide sufficient deformation under seismic force [29]. Special lateral force resistant members, such as buckling restrained braces (BRB) and buckling restrained steel plate shear wall (BRSW), are designed to possess sufficient plastic deformation capacity and energy dissipation capacity [30, 31]. Consequently, HSS members designed with sufficient over strength will not yield during earthquakes. 


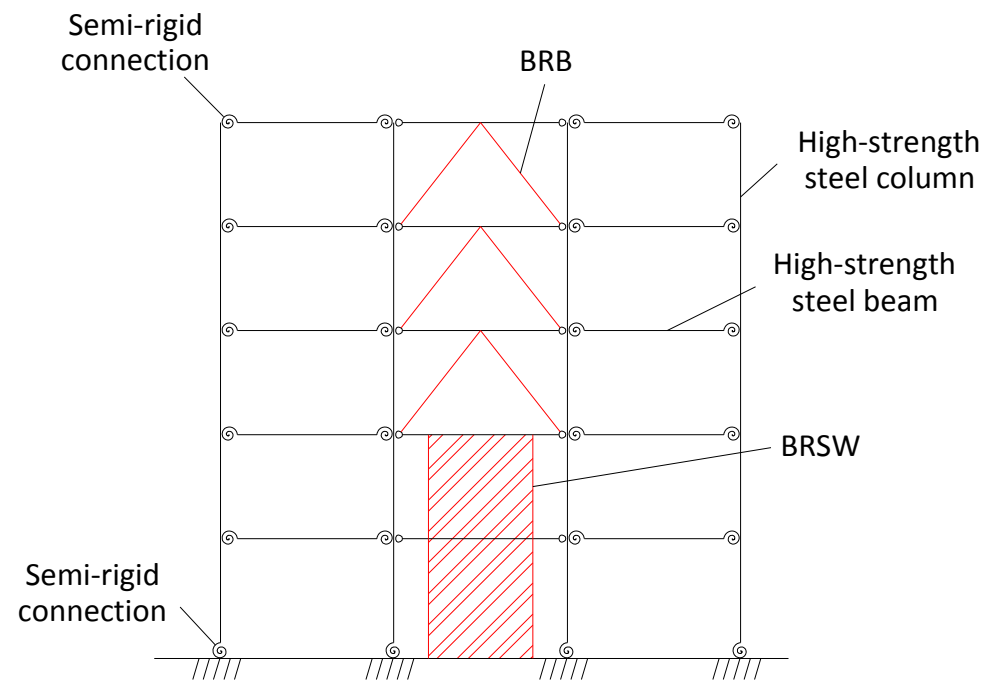

Figure 8. Structure System providing Elastic Design of High-strength Steel Member

The other suggested structural system by Dubina et al. [32] is called dual steel structures (DSS), as shown in Figure 9. DSS is constituted by several bays of HSS moment-resisting frames and at least one bay of eccentrically braced frame with removable links fabricated from normal strength steel or low yield strength steel. The plastic deformations of normal and low yield strength steel members are expected to occur under moderate or rare earthquake actions to reduce the ductility demand of HSS members. The energy dissipation members can behave as fuses of structures. The non-dissipative members are designed with HSS of enough overstrength to prevent inelastic deformation and critical damage. Therefore, HSS frames can sustain the robustness of the gravity load bearing system.

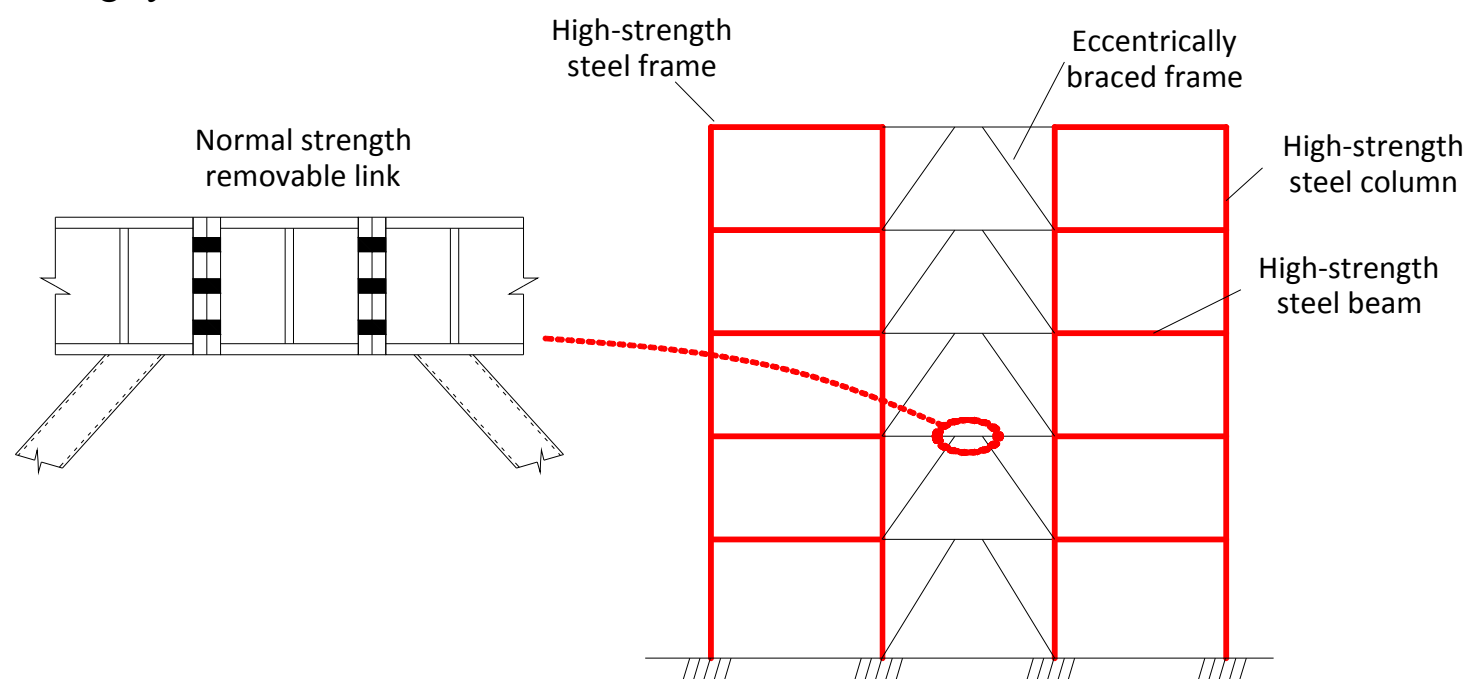

Figure 9. Dual Steel Structure System by Dubina et al. [32]

In those suggested structure systems for HSS structures, energy dissipation members and links are designed as only employed in seismic force-resisting systems instead of bearing gravity load. Therefore, those members and links could be easily replaced if damage occurred after strong earthquake. The interruption of the function and occupation of buildings can be significantly reduced compared with conventional structure systems. 


\subsection{Adjustment of Reliability Index}

Moreover, under probability-based design criteria, the targeted reliability index of members with insufficient ductility could be strengthened to enhance the safety of those members. Structural members are classified into ductile members and brittle members in Unified Standard for Reliability Design of Building Structures GB 50068-2001 [33]. Although HSS members could not meet the material requirements of ductile members as normal strength steel, it is uneconomical to be designed as brittle members since it has considerable ductility higher than that of brittle members. Therefore, a new class named semi-ductile member is suggested, as shown in Table 5 and Table 6. If HSS could not meet the material requirements of ductile member while can meet the material requirements of semi-ductile member, the targeted reliability index of semi-ductile failure should be adopted in the design of HSS members.

Table 5. Classification of Ductility for High-strength Steel Members

\begin{tabular}{cccc}
\hline $\begin{array}{c}\text { Material } \\
\text { properties }\end{array}$ & $\begin{array}{c}\text { Ductile } \\
\text { member }\end{array}$ & $\begin{array}{c}\text { Semi-ductile } \\
\text { member }\end{array}$ & $\begin{array}{c}\text { Brittle } \\
\text { member }\end{array}$ \\
\hline Elongation & $\geq 20 \%$ & $\geq 14 \%$ & $\leq 10 \%$ \\
Y/T & $\leq 0.85$ & $\leq 0.9$ & - \\
\hline
\end{tabular}

Table 6. Targeted Reliability Index of High-strength Steel Members for Ultimate Limit State

\begin{tabular}{cccc}
\hline \multirow{2}{*}{ Failure mode } & \multicolumn{3}{c}{ Important category } \\
\cline { 2 - 4 } & I & II & III \\
\hline Ductile failure & 3.7 & 3.2 & 2.7 \\
Semi-ductile failure & 4.2 & 3.7 & 3.2 \\
Brittle failure & 4.7 & 4.2 & 3.7 \\
\hline
\end{tabular}

\section{RECENT RESEARCH PROGRESS ON SEISMIC BEHAVIOR OF HSS IN TONGJI UNIVERSITY}

\subsection{Material Properties}

The mechanical properties of Q460C and Q690D steel were studied through monotonic-loading and cyclic-loading experiments [34]. The stress-strain relationships were obtained from 40 tensile coupon tests, as shown in Figure 10. It can be seen that the strain hardening of Q460C and Q690D steels is not as significant as normal strength steels. Moreover, for some Q460C coupons, there is even no well-defined yield plateau. The stress-strain hysteretic curves were obtained from the cyclic-loading experiments, as shown in Figure 11a. Based on the generalization of the typical hysteretic curve, each half cycle of hysteretic loops was divided into elastic part, transition part and hardening part. A trilinear kinematic hardening model was used to predict the cyclic response of HSS, with considering the observed Bauschinger effect and cyclic strain hardening, as shown in Figure $11 \mathrm{~b}$. In order to verify the accuracy of the proposed HSS hysteretic model, quasi-static cyclic loading tests of Q460C and Q690D steel beam-column specimens of an accompanied study were simulated and compared. 


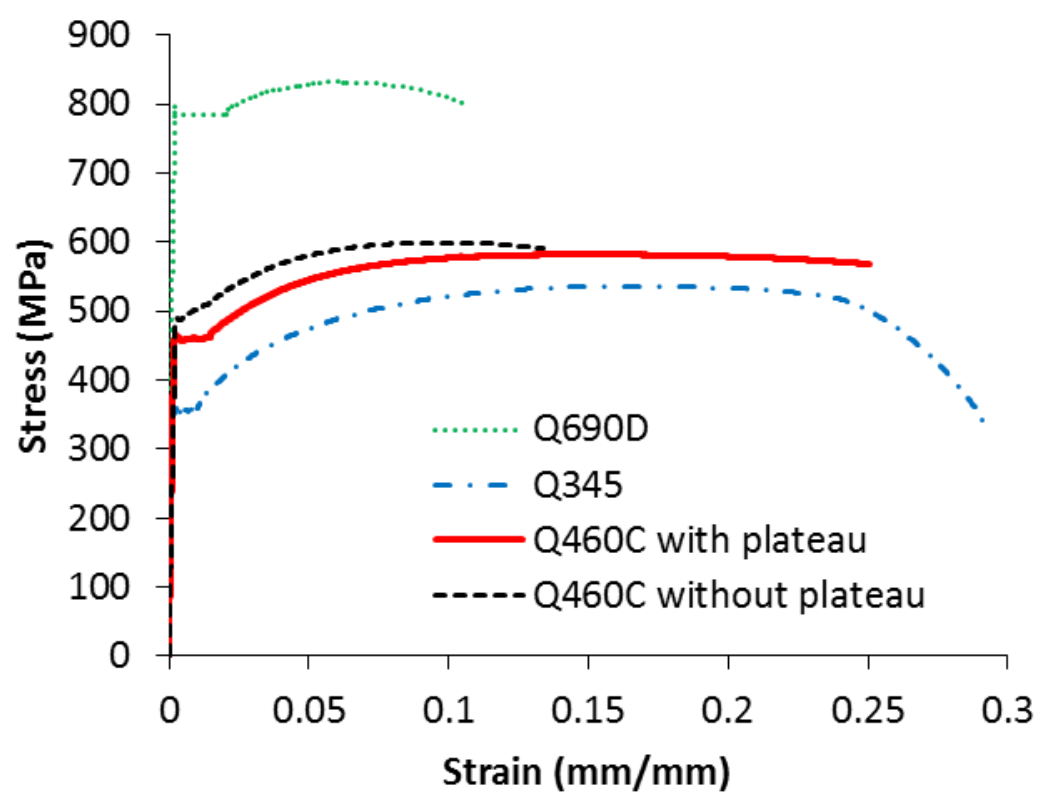

Figure 10. Typical Stress-strain Relationship of Q460C Steel

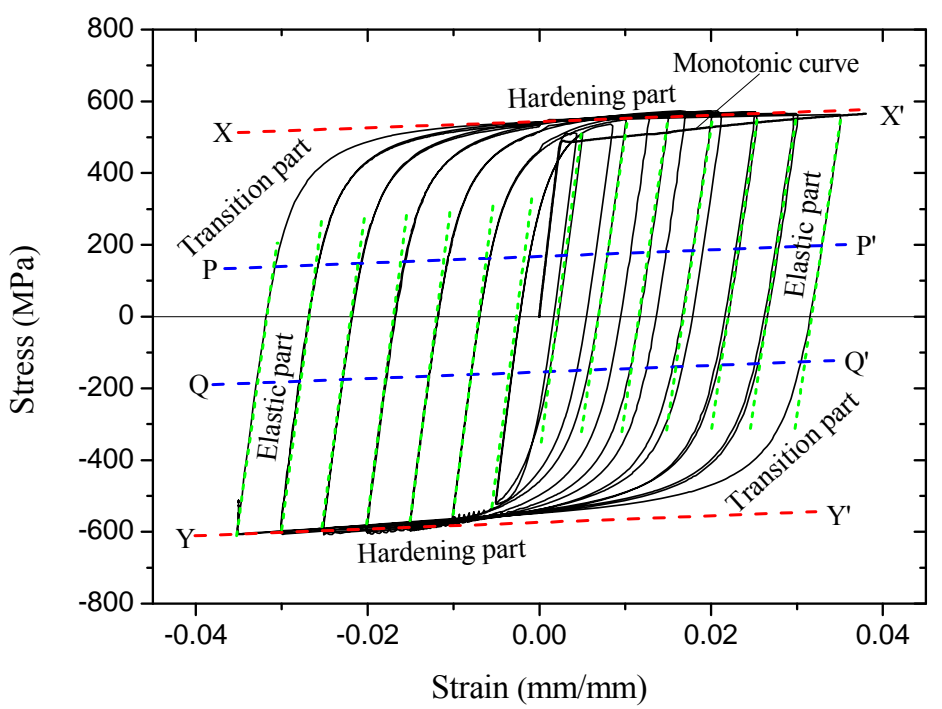

(a) Generalization of the typical hysteretic curve for Q460 steel 


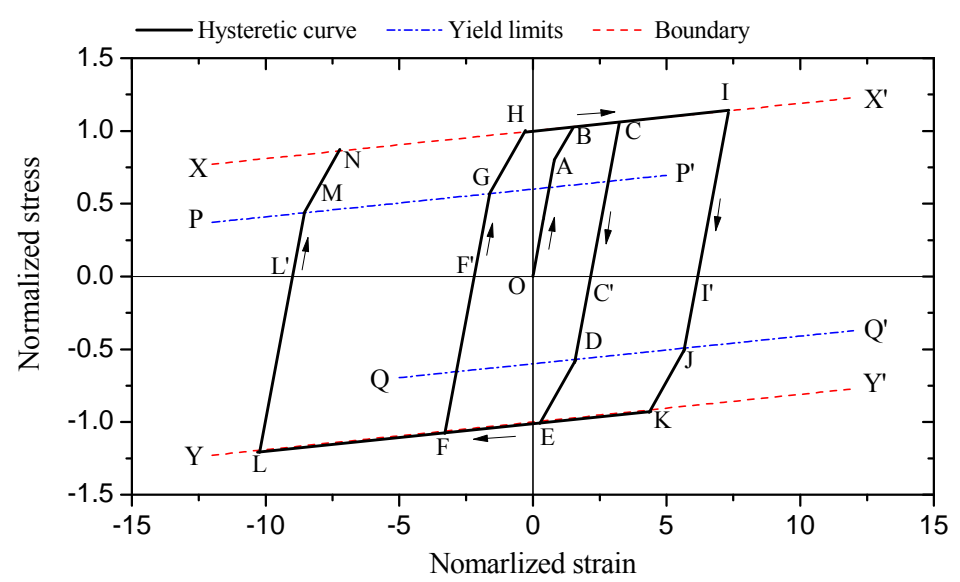

(b) Trilinear kinematic hardening model

Figure 11. Proposed Hysteretic Model for Q460 Steel

\subsection{Hysteretic Behavior}

A total of 12 welded H-section and box-section beam-column specimens with nominal yield strengths of $460 \mathrm{MPa}$ and $690 \mathrm{MPa}$ were tested to evaluate the seismic behavior of HSS members [35]. The fabricated specimens were tested under constant axial loading combined with quasi-static cyclic lateral loading. Ultimate strength, ductility and energy dissipation capacity were evaluated base on the observations of the obtained lateral load-displacement hysteretic curves. All the moment-rotation curves achieved plump hysteretic loops at large storey drift ratio up to $1 / 30$, indicating a good capacity of energy dissipation for the tested HSS H-section and box-section beam-column specimens even under severe earthquake. The effect of cross-sectional geometry on energy dissipation capacity of HSS beam-column members was investigated experimentally and numerically. Moment-curvature hysteretic curves were developed to minimize the influence of the potential slipping and inevitable elastic deformation of the fixed support at column end. Based on the analysis of moment-curvature curves, a trilinear hysteretic model was proposed for HSS welded $\mathrm{H}$-section and box-section columns, as shown in Figure 12. 


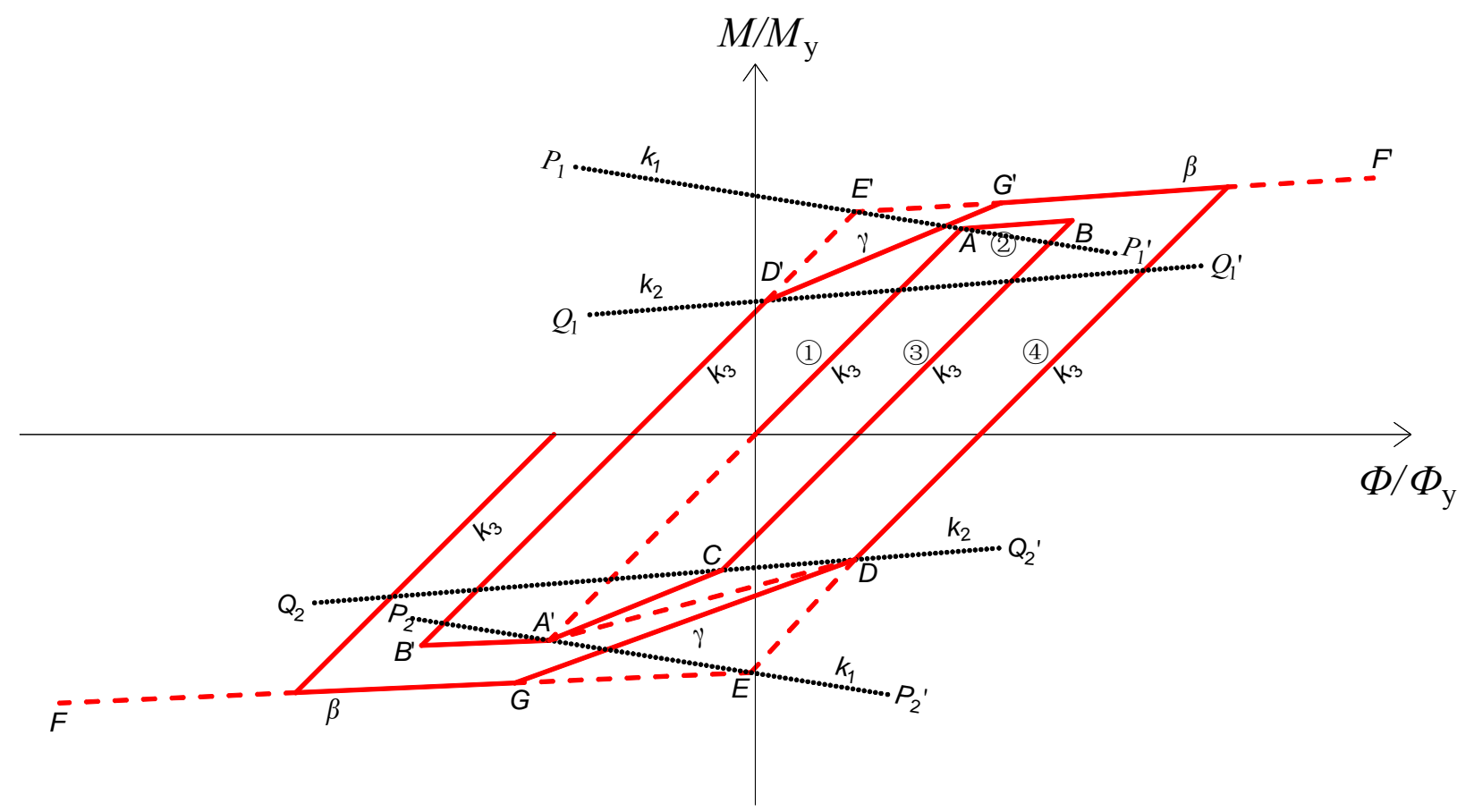

Figure 12. Proposed Moment-curvature Hysteretic Models

\section{CONCLUSION AND RECOMMENDED FUTURE WORK}

Key issues of using high strength steels in seismic structures are discussed. Two design methodologies for HSS seismic resistant structures are proposed. Recent research work on the seismic performance of high-strength steel conducted at Tongji University is introduced. The effect of reheating and cooling during fabrication process on the mechanical properties of HSS is evaluated. The significant reduction of the strength of HSS by reheating should be considered in seismic design. Although certain efforts have been achieved on HSS structures, future research work is necessary, as suggested below, to include HSS in the structural design specifications.

(1) Statistic research of material properties and determination of partial factors for resistance;

(2) Ultimate bearing capacity and deformability of fundamental HSS members;

(3) Hysteretic behavior and hysteretic model of HSS beam and beam-column;

(4) Connections of HSS members;

(5) Fatigue behavior of HSS members and connections;

(6) Structural system for HSS structures;

(7) Determination of targeted reliability index and partial factors for actions;

(8) Determination of design earthquake action and criteria for performance-based design.

\section{ACKNOWLEDGEMENTS}

This study was supported by the Ministry of Science and Technology of China (Grant No. 2012BAJ13B02) and China Postdoctoral Science Foundation (Grant No. 2014M561518), which are gratefully acknowledged. 


\section{REFERENCES}

[1] Rosier, G.A., Croll, J.E., "High Strength Quenched and Tempered Steels in Structures Seminar Papers of Association of Consulting Structural Engineers of New South Wales", Steel in Structures, Sydney, Australia, 1987.

[2] Pocock, G., "High Strength Steel use in Australia, Japan and the US", Structural Engineer, 2006, Vol. 84, pp. 27-30.

[3] Collin, P. and Johansson, B., "Bridges in High Strength Steel", Responding to Tomorrow's Challenges in Structural Engineering", IABSE Symposium, Zurich, Switzerland, ETH Honggerberg, 2006, pp. 434-5.

[4] World Steel Association, Annual Crude Steel Production Archive, http://www.worldsteel.org/statistics/statistics-archive/annual-steel-archive.html. 2012.

[5] World Coal Association. Coal Statistics - Coal Facts 2011, http://www.worldcoal.org/resources/coal-statistics/. 2011.

[6] GB 50017-2003, Code For Design of Steel Structures. Beijing: China Architecture \& Building Press, 2003 (in Chinese).

[7] GB 50011-2010. Code for seismic design of buildings Beijing: China Architecture \& Building Press, 2010 (in Chinese).

[8] Kato, B., "Deformation Capacity of Steel Structures", Journal of Constructional Steel Research, 1990, Vol. 17, pp. 33-94.

[9] Kato, B., "Role of Strain-hardening of Steel in Structural Performance", ISIJ International, 1990, Vol. 30, pp. 1003-9.

[10] Earls, CJ., "Influence of Material Effects on Structural Ductility of Compact I-Shaped Beams", Journal of Structural Engineering. 2000, Vol. 126, pp. 1268-78.

[11] CEN. Eurocode 3: Design of Steel Structures, Part 1-1: General Rules and Rules for Buildings, EN 1993-1-1. Brussels: European Committee for Standardization, 2005.

[12] CEN. Eurocode 8: Design of Structures for Earthquake Resistance, Part 1-1: General Rules, Seismic Actions and Rules for Buildings, EN 1998-1. Brussels: European Committee for Standardization, 2004.

[13] Fukumoto, Y., "New Constructional Steels and Structural Stability", Engineering Structures, 1996, Vol. 18, pp. 786-91.

[14] GB/T 19879-2005. Steel Plates for Building Structure, 2005.

[15] GB/T 1591-2008. High Strength Low Alloy Structural Steels, 2008.

[16] Earls, C.J., "Suitability of Current Design Practice in the Proportioning of High Performance Steel Girders and Beams", Proceedings of the 17th International Bridge Conference, Pittsburgh: Engineers' Society of Western Pennsylvania, 2000, pp. 91-8.

[17] Green, P.S., Sause, R. and Ricles, J.M., "Strength and Ductility of HPS Flexural Members", Journal of Constructional Steel Research, 2002, Vol. 58, pp. 907-41.

[18] Earls, C.J. and Shah, B.J., "High Performance Steel Bridge Girder Compactness", Journal of Constructional Steel Research, 2002, Vol. 58, pp. 859-80.

[19] Sause, R. and Fahnestock, L.A., "Strength and Ductility of HPS-100W I-Girders in Negative Flexure", Journal of Bridge Engineering, 2001, Vol. 6, pp. 316-23.

[20] Rasmussen, K.J.R. and Hancock, G.J., "Plate Slenderness Limits for High Strength Steel Sections", Journal of Constructional Steel Research, 1992, Vol. 23, pp. 73-96.

[21] Rasmussen, K.J.R. and Hancock, G.J., "Tests of High Strength Steel Columns", Journal of Constructional Steel Research, 1995, Vol. 34, pp. 27-52.

[22] Ban, H., Shi, G., Shi, Y. and Wang, Y., "Overall Buckling Behavior of $460 \mathrm{MPa}$ High Strength Steel Columns: Experimental Investigation and Design Method", Journal of Constructional Steel Research, 2012, Vol. 74, pp. 140-50. 
[23] Wang, Y-B., Li, G-Q., Chen, S-W. and Sun, F-F., "Experimental and Numerical Study on the Behavior of Axially Compressed High Strength Steel Columns with H-section", Engineering Structures, 2012, Vol. 43, pp. 149-59.

[24] Wang, Y-B., Li, G-Q., Chen, S-W. and Sun, F-F., "Experimental and Numerical Study on the Behavior of Axially Compressed High Strength Steel Box-columns", Engineering Structures, 2014, Vol. 58, pp. 79-91.

[25] Dusicka, P., Itani, A.M. and Buckle, I.G., "Cyclic Response of Plate Steels under Large Inelastic Strains", Journal of Constructional Steel Research, 2007, Vol. 63, pp. 156-64.

[26] Shi, G., Wang, M., Bai, Y., Wang, F., Shi, Y. and Wang, Y., "Experimental and Modeling Study of High-strength Structural Steel under Cyclic Loading", Engineering Structures, 2012, Vol. 37, pp. 1-13.

[27] CEN. Hot Rolled Products of Structural Steels, Part 6: Technical Delivery Conditions for Flat Products of High Yield Strength Structural Steels in the Quenched and Tempered Condition, EN 10025-6. Brussels: European Committee for Standardization, 2004.

[28] GB/T 228-2002 Metallic Materials: Tensile Testing at Ambient Temperature, Beijing: China Standard Press, 2002 (in Chinese).

[29] Shi, W.L., Li, G.Q., Ye, Z.M. and Xiao, R.Y., "Cyclic Loading Tests on Composite Joints with Flush End Plate Connections", International Journal of Steel Structures, 2007, Vol. 7, pp. 119-28.

[30] Lu, Y. and Li, G.Q., "Slim Buckling-restained Steel Plate Shear Wall and Simplified Model", Advanced Steel Construction, 2012, Vol. 8, pp. 282-94.

[31] Li, G.Q., Sun, F.F., Chen, S.W. and Guo, X.K., Application of Buckling-Restrained Braces in Steel Frameworks against Earthquakes, 2010.

[32] Dubina, D., Stratan, A. and Dinu, F., "Dual high-strength Steel Eccentrically Braced Frames with Removable Links", Earthquake Engineering and Structural Dynamics, 2008, Vol. 37, pp. 1703-20.

[33] GB 50068-2001. Unified Standard for Reliability Design of Building Structures, Beijing: China Architecture \& Building Press, 2001 (in Chinese).

[34] Wang Y-B, Li G-Q, Cui W, Chen S-W, Sun F-F. Experimental investigation and modeling of cyclic behavior of high strength steel. Journal of Constructional Steel Research. 2015; 104:37-48.

[35] Wang Y-B, Li G-Q, Cui W, Chen S-W. Seismic behavior of high strength steel welded beam-column members. Journal of Constructional Steel Research. 2014;102:245-255. 